\title{
Does more and better research result in greater and effective impact?
}

Scholars from almost all disciplines play - directly or indirectly - at least two major roles in relation to publishing the results of their research. The first, and most obvious, is that they share their research findings with fellow researchers, to add to and enrich (it is to be hoped) the store of knowledge in their field, and to enable debate around the nature of their findings. The second, while almost as important but less obvious, is that they share their findings and the implications of their findings with the public at large, including policy- and decision-makers.

Writing in the Scholarly Kitchen late last year, David Crotty ${ }^{1}$ pointed out that 'Publishing is a service business, and over time, offering that service to the broader community has become one of the main ways that [can generate funding]'. A recent article published in the South African Journal of Science shows clearly how important both roles are in adding to knowledge, informing the pubic of important issues - and generating considerable debate. Within 2 weeks of its publication, Jennifer Fitchett's ${ }^{2}$ article on CAT5 tropical storms in the South Indian Ocean received 450 views on the journal website and reached an audience of over 800 on Facebook and 3500 on Twitter; the article was also reported on by seven major print and online newspapers. So, as well as being read (and debated) by scientists in the fields of climatology and climate change, the paper has been accessible to the wider public. Most of the broader audience agree with the conclusions of the paper, some (inevitably) disagree, but the issue is that, whether through the journal website or a media report, a wider community of readers has been able to access the findings of the paper and give consideration to their implications.

Assessing the extent to which scholarly publishing in South Africa is developing and changing is, therefore, an important role for the Academy of Science of South Africa (ASSAf). The information arising from this role is also an important source for scholars in general (including for their own disciplines), and especially for those who work in the fields of bibliometrics and scientometrics. As a result, ASSAf commissioned a Consensus Report on Research Publishing in South Africa ${ }^{3}$ which was published in 2006. From the start, the report stated that:

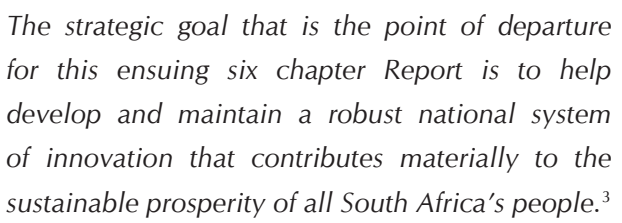

In other words, the work addressed not only the two roles of scholarly publishing with which this Leader opened - but extended the significance of both into the realm of contributing 'materially' (substantively) to the greater social good.

The Introduction made it clear that, amongst other things, 'South Africa occupies the paradoxical position in the arena of research publishing of being a dwarf internationally and a giant on the African continent'.
It went on to report that about 3500 papers with at least one South African author address were indexed by the then Institute for Scientific Information (ISI) in 2000 , representing about $0.5 \%$ of all papers in the three major databases of that system, covering approximately 5500 selected international journals in science, engineering and medicine, 1800 in the social sciences, and 1200 in the arts and humanities. ${ }^{3}$

A second report by ASSAf titled Twelve Years Later: Second ASSAf Report on Research Publishing in and from South Africa (2018) ${ }^{4}$ will be released in 2019. Some remarkable changes have taken place in the field of scholarly publishing over those 12 years. A few conditions remain more or less the same - but the fundamental issue of the public good has not changed, other than to be even clearer now. Not unexpectedly, this report is longer and more detailed, and draws on a number of focused research projects in the fields of bibliometrics and scientometrics that have been conducted since 2006 . The new report benefits, then, from vastly more data than were available 12 years ago.

Disappointingly, the 2006 assessment that South Africa is 'a giant on the African continent' still holds true. Research output has improved in a number of African countries, but the improvement in South Africa outweighs those changes, with South Africa still producing over $50 \%$ of Africa's output (which totals somewhere between $1 \%$ and $2 \%$ of global research publications depending on how the figures are calculated).

The South African increase is substantial: from 3550 publications noted in the 2006 report to 15542 for 2014 . This growth has moved South Africa from 34th to 28th position in the list of top research producing countries in the world.

The Twelve Years Later report provides valuable insights, backed by substantial sets of data, into the changes that have taken place since the publication of the 2006 report, for books and chapters in books, apart from journal articles.

Which brings us back to the beginning. Set against the improvements, however, is the question of the impact that the great improvements in research output have had and are having on the public and on policyand decision-makers. Does research on innovation lead to greater, and more effective innovation? Or do papers on the likely impacts of climate change or of fracking have an impact on government policies and actions? If not, there are significant audiences still to be reached and convincing cases to be made.

\section{References}

1. Crotty $D$. Why society and not-for-profit journals are worth preserving: Better economic and continuing value for the community. The Scholarly Kitchen [blog online]. 2018 December 06 [cited 2018 Dec 12]. Available from: https:// scholarlykitchen.sspnet.org/?s=society + and + not-for-profit+ journals

2. Fitchett J. Recent emergence of CAT5 tropical cyclones in the South Indian Ocean. S Afr J Sci. 2018;114(11/12), Art. \#4426, 6 pages. https://doi. org/10.17159/sajs.2018/4426

3. Academy of Science of South Africa (ASSAf). Report on a strategic approach to research publishing in South Africa. Pretoria: ASSAf; 2006. http://hdl. handle.net/20.500.11911/49

4. Academy of Science of South Africa (ASSAf). Twelve years later: Second ASSAf report on research publishing in and from South Africa (2018). Pretoria: ASSAf; 2018. 